\title{
Effect of Pocket Die Bearing Geometry on Direct Cold Extrusion Process Responses
}

\author{
Terfa Gundu*, Livinus Tuleun, Oryina Injor \\ Department of Mechanical Engineering, University of Agriculture, Makurdi-Nigeria \\ *Corresponding author: dtergundu@yahoo.com
}

Received May 21, 2014; Revised June 03, 2014; Accepted June 15, 2014

\begin{abstract}
In this paper, an extensive direct extrusion program was designed to experimentally investigate the effects of die bearing geometry parameters with a view to achieving reduced extrusion loads and product deflection. Using soft aluminiumalloy as extrusion material, flat and conical pocket die bearing geometries were considered, and geometry parameters of die angle, bearing length, pocket depth and offset were varied to obtain corresponding responses of extrusion pressure and extrude deflection. Results showed that for conical pocket geometry, increasing entrant angle reduced extrusion pressure to a minimum value at the included die angle of $90^{\circ}$, and then increased gradually with further increase in die angle. Extrudes deflections are reduced as die angle is increased. Increasing the die bearing length increased extrusion pressure but extrudes deflection is reduced. For flat pockets, increasing the pocket depth increased extrusion pressure, but for conical pockets, extrusion pressure is reduced. For both geometries, extrudes deflection is reduced as pocket depth is increased. Both extrusion pressure and extrudes deflection are reduced increasing pocket offset. It is concluded that extrusion pressure and extrudes deflection can be controlled using these die geometry parameters. Better flow conditions are however obtained with conical die geometries to achieve minimized extrusion loads and product curvature.
\end{abstract}

Keywords: extrusion pressure, extrudes deflection, die bearing geometry, die angle, bearing length, pocket depth, pocket offset

Cite This Article: Terfa Gundu, Livinus Tuleun, and Oryina Injor, "Effect of Pocket Die Bearing Geometry on Direct Cold Extrusion Process Responses.” American Journal of Mechanical Engineering, vol. 2, no. 3 (2014): 65-69. doi: 10.12691/ajme-2-3-3.

\section{Introduction}

There has been considerable interest in the investigation on the effects of die geometry and other extrusion parameters on the flow patterns, extrusion pressure and mechanical properties of shaped sections [1,2,3]. In recent years more attention has been given to the study of the bearing area because it has the dominant influence on the characteristics of the extrusion process [4-9]. The results of a study on cold extrusion of aluminum and lead alloys shapes of inner circular sections with four symmetrical projections indicated that both maximum and coring extrusion pressures were affected by the die entrant angle and reduction in area of the cross-sections [4]. These values were found to be minimized at a die entrant angle of $90^{\circ}$. The results also indicated that product curvature is also dependent on these variables. Another study also recommended the use of tapered billets to reduce extrusion pressure. The results of a related study on the effect of die shape on the state of strain during hot extrusion of thin-walled aluminum T-sections indicate that product deflection or bending can be controlled by the antechamber height and shape $[5,6,7]$. This suggests that a parallel bearing over some length $L$ is essential to control product curvature or bending. Balance of flow is critically important for sections with varying thickness; thicker wall sections flow faster than thinner ones and areas near the centre of the die flow faster than near the container walls. Simulating the effect of extrusion parameters and die geometry on product quality [8] also found that the extrusion die radius influenced material flow by increasing the von-Misses strains as the die radius was increased. However, owing to difficulty to practically produce the die geometry to the desired die radius, the results of the simulations could not be experimentally validated. Simulations of multi-hole extrusion of aluminum alloy tubes also reported by [9] in which they measured bending angles at the tip of the extruded tubes to assess the effect of extrusion temperature, speed and billet dimension on tube shape. They found that these variables had significant effect on the final tube shape and quality.

Traditionally, flow control has been achieved using different bearing configurations: from shear to slip dies, dies with relieved bearings, dies with pocket bearings, etc. Each of these achieves improvements in product quality or a reduction in extrusion pressure at the expense of the other. Extrusion flow control has been achieved using variable bearing lengths; the length of the bearings over which the metal passes is adjusted locally so that the frictional forces act to balance any asymmetry of velocity [10]. The disadvantage of this method is that the bearings generate heat due to friction which limits the extrusion 
speeds attainable before poor surface quality or localized tearing of the extrudes occurs. For this reason, the shortest possible bearings are preferred [11,12,13].

Although shear dies are ideal for aluminum, they are not suitable for extrusion of composites, polymers and certain alloys which work better with streamlined or shaped dies which allow for smooth material flow, a more homogenously deformed product, lower extrusion pressures, and no intense shear band. Streamlined dies are however limited to simple and somewhat symmetrical shapes. Usually, extrusion is carried out at very high temperatures, and in the case of shear or flat- face dies with intense shearing of metal, there are possibilities of adiabatic heating or hot shortness occurring during the extrusion process. Knife-edged dies or relieved bearings would give reduced extrusion pressures, but would easily wear out and require frequent resurfacing to maintain the desired product dimensions and increased product curvatures $[14,15,16]$. Parallel bearings can result to increased resistance in the bearing channel and unpredictability of the extrusion process [17]. Similarly, pocket bearings achieve uniform exit velocity in the entire bearing section but like parallel bearing, result to increased resistance. This is essentially a shear die with a feeder plate with knife-edges at the entrant side, and zero bearing length [18].

Material flow can also be controlled using a shaped pocket, (sink-in or feeder) in front of the die to enable the use of short bearings. The appropriate design of the pocket will help in regulating material flow and lead to a single bearing length or even zero length bearings. This is preferred to a flat die with varying bearing lengths as a pocket die could be easier to machine or correct especially for extrusion of a thin walled profile. A pocket die is usually required for extrusion of complex geometries. A fundamental understanding of pocket design is currently inadequate, and depends primarily on the experience of the die designer [19]. Limited work has been done towards systematically examining influences of the pocket geometries and offsets on metal flow. There is need, therefore, to design the die in such a way that the advantages of both streamlined and shear dies can be achieved with consideration for product bending.

The aim of the current study was to evaluate the effect of die bearing geometry parameters of die angle, die bearing length, pocket depth and offset on extrusion load and extrudes deflection with a view to obtaining optimum metal flow conditions.

\section{Experimental Methodology}

\subsection{Extrusion Procedure}

The aluminium alloy was melted and cast in galvanized steel moulds to Ø26 mm.AAS elemental composition and material properties of the alloy are given in Table 1 and Table 2 respectively. Extrusion billets were machined to $\varnothing 25.4 \mathrm{~mm} \times 26 \mathrm{~mm}$, and were direct extruded on the manual ELE Compact-1500 hydraulic compression testing machine as shown on Figure 1. Shear butter was used as lubricant, and the extrusion rig was washed with caustic soda after every extrusion. Average maximum values of extrusion loads were obtained for each extrusion at the steady stage of the process $[1,20]$. The extrusion rig was designed for direct and backward extrusion of aluminium and other light alloys, and consisted of a cylindrical thickwalled steel container and an inner insert to provide the extrusion chamber, which together with the extrusion dies and ram formed the extrusion assembly.

Table 1. AAS Composition of Aluminium Alloy

\begin{tabular}{|c|c|c|c|c|c|}
\hline \multicolumn{6}{|c|}{ Elements } \\
\hline $\mathrm{Al}$ & $\mathrm{Si}$ & $\mathrm{Mg}$ & $\mathrm{Fe}$ & $\mathrm{Cu}$ & Others \\
\hline 98.69 & 0.42 & 0.3 & 0.2 & 0.1 & 0.29 \\
\hline
\end{tabular}

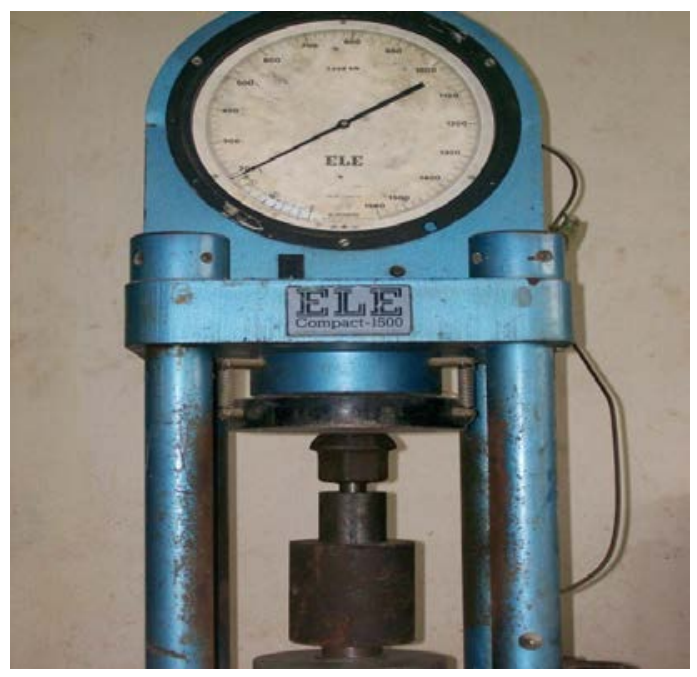

Figure 1. Extrusion Setup

Table 2. Material Properties of Aluminum Alloy

\begin{tabular}{|c|c|c|}
\hline Process parameter & Metric units $\left(\mathrm{m} / \mathrm{N} / \mathrm{s} /{ }^{\circ} \mathrm{K}\right)$ & \\
\hline Ram speed & $\mathrm{m} / \mathrm{s}$ & manual \\
\hline Density (p) & $\mathrm{Kg} / \mathrm{m}^{3}$ & 2635 \\
\hline Tool Temperature $\left(\mathrm{T}_{\mathrm{c}}, \mathrm{T}_{\mathrm{k}}\right)$ & K & 309 \\
\hline Initial Billet Temperature $\left(\mathrm{T}_{\mathrm{b}}\right)$ & $\mathrm{K}$ & 309 \\
\hline Young's Modulus (E) & $\mathrm{Pa}$ & $69.655 \times 10^{9}$ \\
\hline Minimum Yield Stress (S) & $\mathrm{Pa}$ & $8.5 \times 10^{7}$ \\
\hline Yield Stress Constant (C) & $\mathrm{Pa}$ & $34.531 \times 10^{7}$ \\
\hline Strain Hardening Exponent (n) & - & 0.209 \\
\hline Poisson’s Ratio & - & 0.33 \\
\hline
\end{tabular}

Flat pocket dies for determining the effect of pocket geometry on extrusion parameters, were produced to a die reduction ratio $\mathrm{R}$ of $0.3(\varnothing 14 \mathrm{~mm})$. One set of dies was produced according to Figure 2 to varying depths $(\mathrm{H})$ of 3 , 4, 5, 6 and $7 \mathrm{~mm}$ at offset (o) of $2.0 \mathrm{~mm}$; another set to varying offsets (o) of 1.0, 1.5, 2.0, 2.5 and $3.0 \mathrm{~mm}$ at a depth of $4.0 \mathrm{~mm}$. Conical pocket dies were produced according to Figure 3 to $\varnothing 14 \mathrm{~mm}$ and die entrant angles of $60^{\circ}, 75^{\circ}, 90^{\circ}, 105^{\circ}, 120^{\circ}, 150^{\circ}$ and $180^{\circ}$.

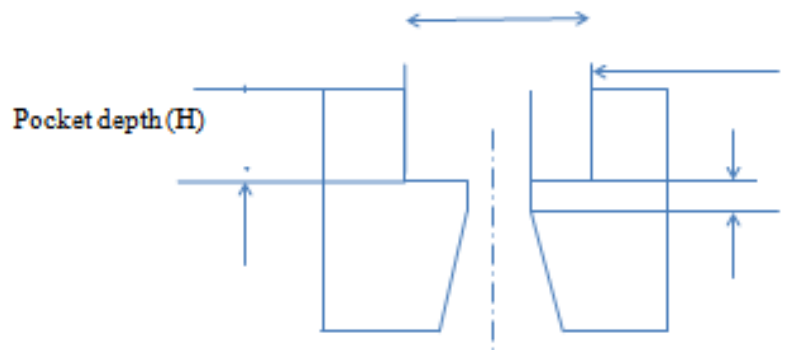

Figure 2. Flat pocket die 


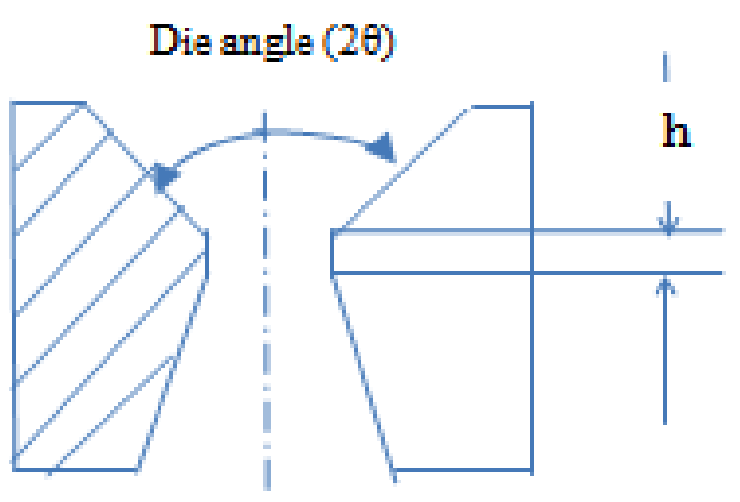

Figure 3. Conical pocket with parallel bearing

\subsection{Measuring Extrudes Deflections}

After extrusion, extrudes were carefully separated from the dies and were held on lathe machine using three-jaw chuck. By rotating the chuck, maximum axial deflections were measured at $25 \mathrm{~mm}$ from the chuck face using a vertical height gauge as shown on Figure 4.

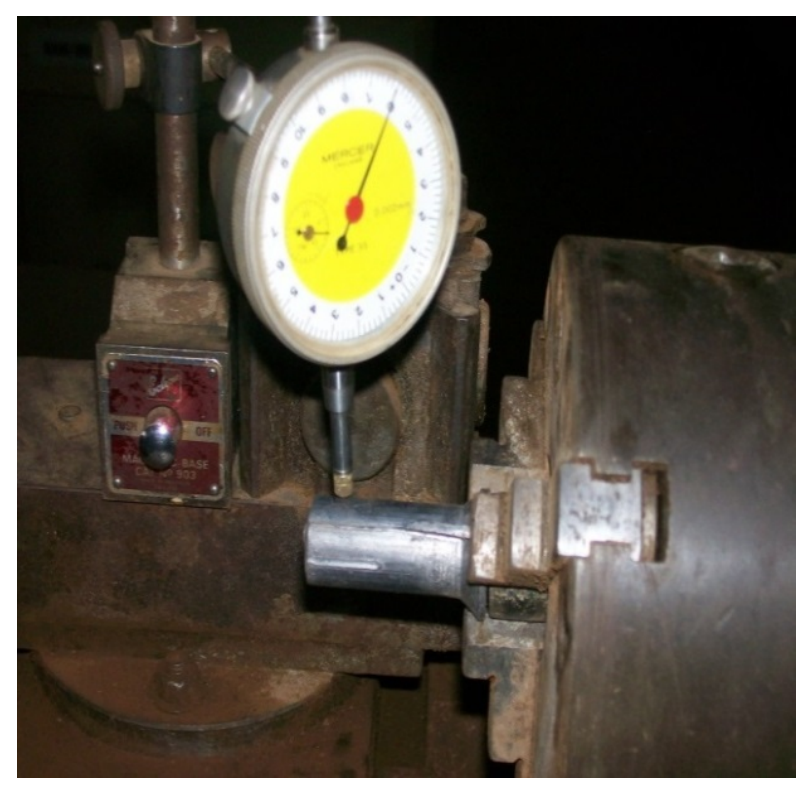

Figure 4. Setup for measuring extrudes deflections

\section{Results and Discussion}

\subsection{Effect of Die Angle}

Figure 5 showed that at all reduction ratios, increasing entrant angle reduced extrusion pressure to a minimum value at the included die angle of $90^{\circ}$, and then increased gradually with further increase in die angle. The reduced extrusion pressure at $90^{\circ}$ die angle is due to the least redundancy energy at the shear angle of $45^{\circ}$ for most metals [21], by which extrusion flow is mostly by slip. It is also observed that extrusion pressure is higher for included entrant angles below $90^{\circ}$. As shown on Figure 6, a gradual reduction in extrude deflections are obtained as die angles are increased. These results generally agree with earlier findings by [4] which indicated constant curvature (radius) between die angles of $60^{\circ}$ and $120^{\circ}$, and rapid increase beyond the die angle of $120^{\circ}$. Die angles result to formation of a pocket in front of the die orifice, thereby creating conditions for improved flow. At a die angle of $180^{\circ}$, the formation of dead metal zone will cause an increase in extrusion resistance but control of material flow is achieved resulting in lower extrudes deflections and curvatures.

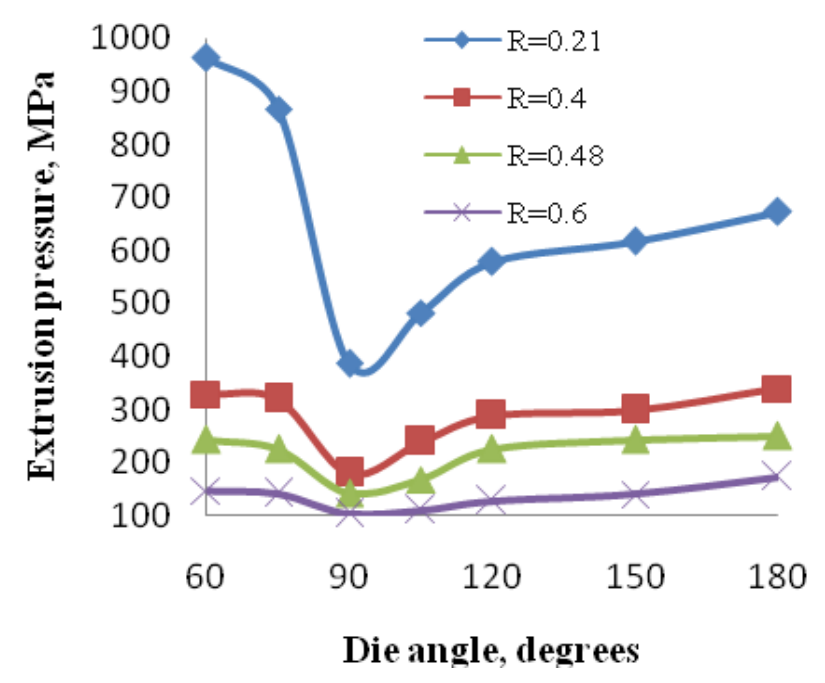

Figure 5. Extrusion pressure vs die angle

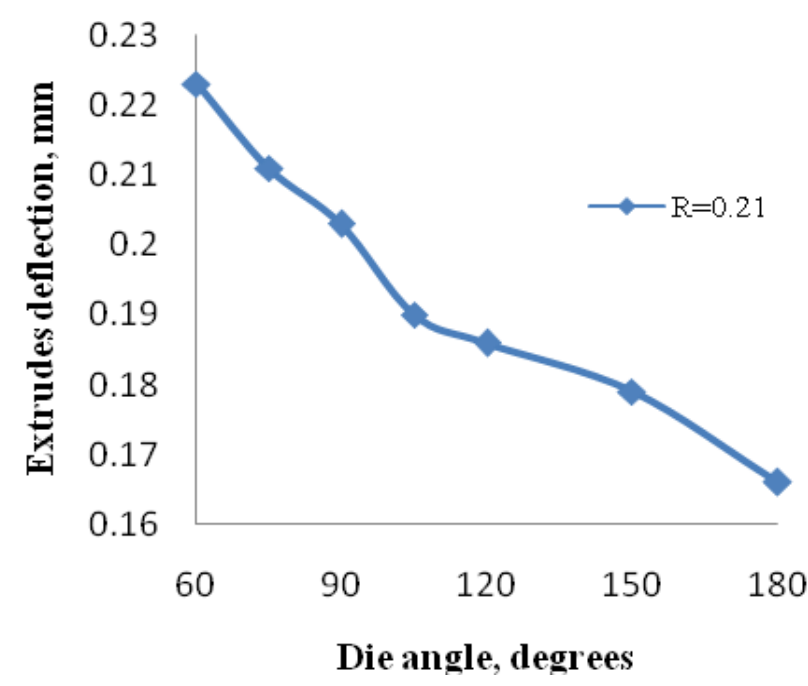

Figure 6. Extrudes deflection vs die angle

\subsection{Effect of Die Bearing Length}

Figure 7 showed that at all die reductions increasing the die bearing length increased extrusion pressure. The results generally agree with the findings of a related study by [17] which simulated aluminum flow in the bearing area for extrusion of thin- walled sections. The results also confirm earlier findings by $[10,22,23]$ that the extrusion (friction) force increases as the die land is increased. As shown on Figure 8 lower extrude deflections were obtained with dies of larger bearing lengths, and extrude deflections tend towards zero as die bearing length becomes large, while extrude curvature radii becomes infinite. This is an indication of straightness, and from the results minimum section bending was obtained for $\frac{\Delta \delta}{\Delta L}=0$ at a bearing length $\mathrm{L}$ of $15.85 \mathrm{~mm}[4,7]$. A similar study by [5] had obtained minimum section bending of thin-walled sections by increasing the antechamber height and surface area, achieving an optimal height $h$ of $14.642 \mathrm{~mm}$ for $\mathrm{R}=0.21$. 


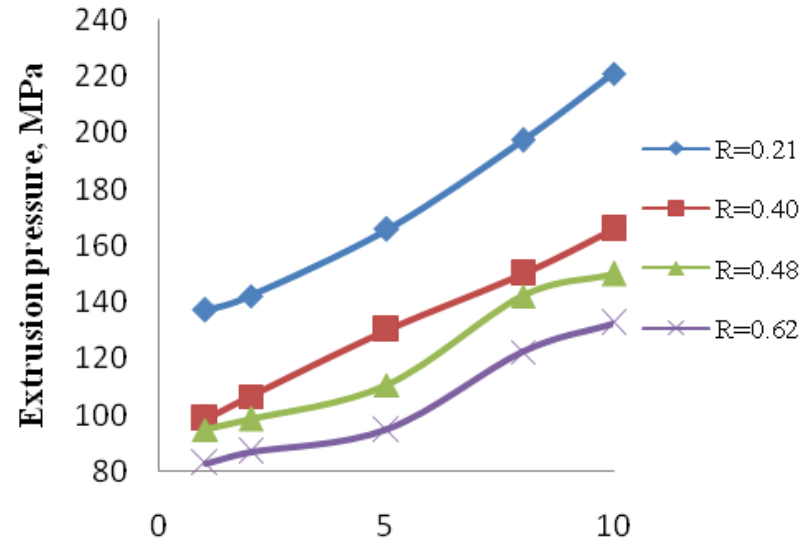

Die bearing length, mm

Figure 7. Extrusion pressure vs die bearing length

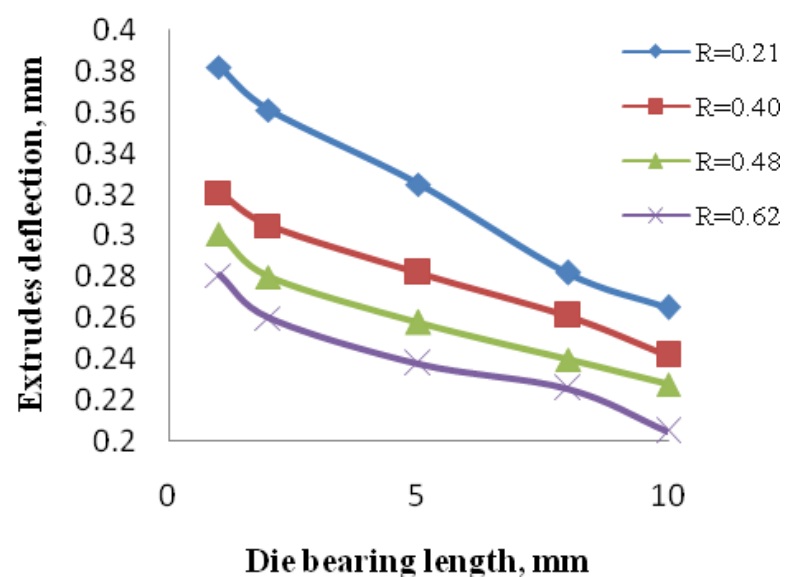

Figure 8. Extrudes deflection vs die bearing length

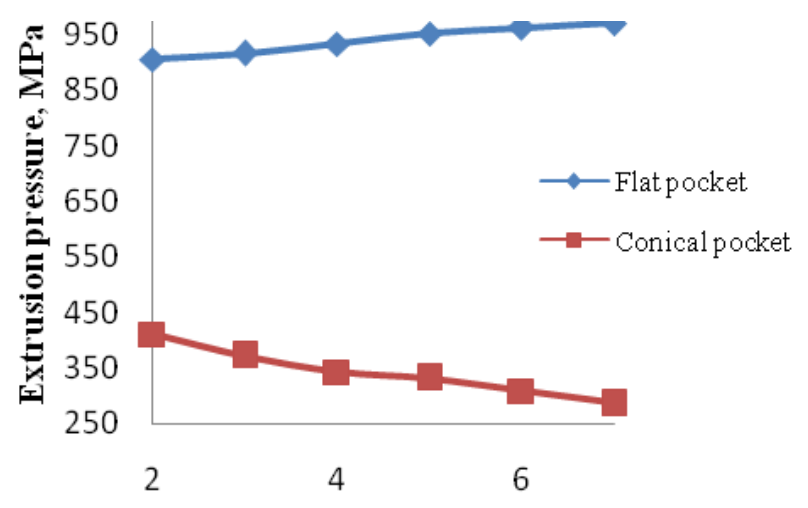

Pocket depth, mm

Figure 9. Extrusion pressure vs pocket depth

\subsection{Effect of Pocket Depth}

The effect of pocket depth on extrusion pressure varies with pocket geometry. Figure 9 showed that for flat pockets, increasing the pocket depth increased extrusion pressure. As the pocket deepens, the die bearing is essentially a parallel channel with two shear fronts and increased friction surface, and as found by [22], unstable and unpredictable behaviour can be expected from the parallel channel. For conical pockets, increasing the pocket depth reduced extrusion pressure. The reduction may be explained by the fact that as with shear dies, the friction surface is also increased, but extrusion is largely by slip mechanism at reduced pressures. As shown on Figure 10, increasing the pocket depth reduced extrudes deflection for both flat and conical die pocket geometries owing to improved material flow condition in front of the die orifice as reasoned by [4].

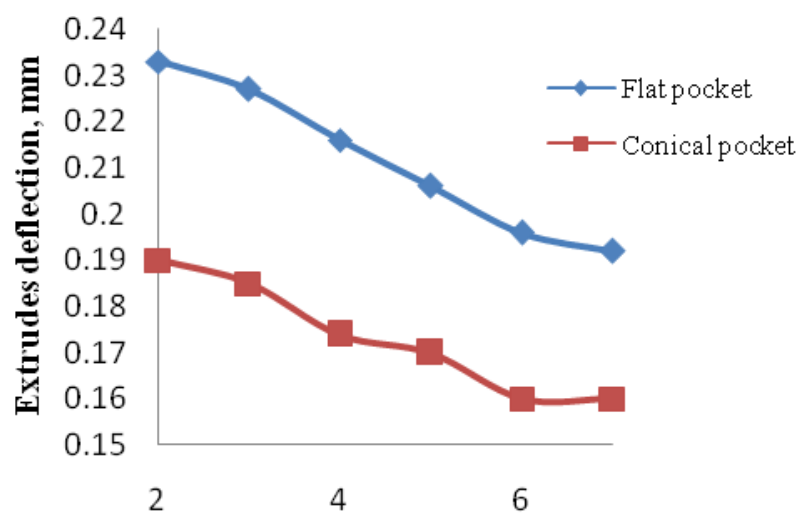

Pocket depth, mm

Figure 10. Extrudes deflection vs pocket depth

\subsection{Effect of Pocket Offset}

The effect of pocket offset on extrude deflections varies with pocket geometry. Figure 11 showed that for flat pocket, increasing the pocket offset (o) reduced extrusion pressure in agreement with findings of the study by [19]. The results indicate that with both pocket geometries, material flow is not homogeneous at the initial stage of extrusion. This further confirms the findings of a study by [12] which investigated inhomogeneous metal flow in aluminium extrusions with three-dimensional complex geometries, that even a slight inhomogeneity of metal flow can significantly affect the final geometry of extrudes [25] also found that such non-uniform flow causes cross cracking, bending, distortion and twisting of extrudes. Figure 12 showed that increasing the offset size between the edge of the pocket and the edge of the die orifice reduced extrudes deflection. This is attributed to improved flow in the die bearing in line with the findings of $[13,19,26]$ using similar methods, that small offsets lead to slow flow velocity, but large offsets results in higher velocity and allow for easier flow of the material and hence, reduced curvature. The results also agree with the findings of a study by [8] that billet quality is affected by the die geometry among other extrusion parameters.

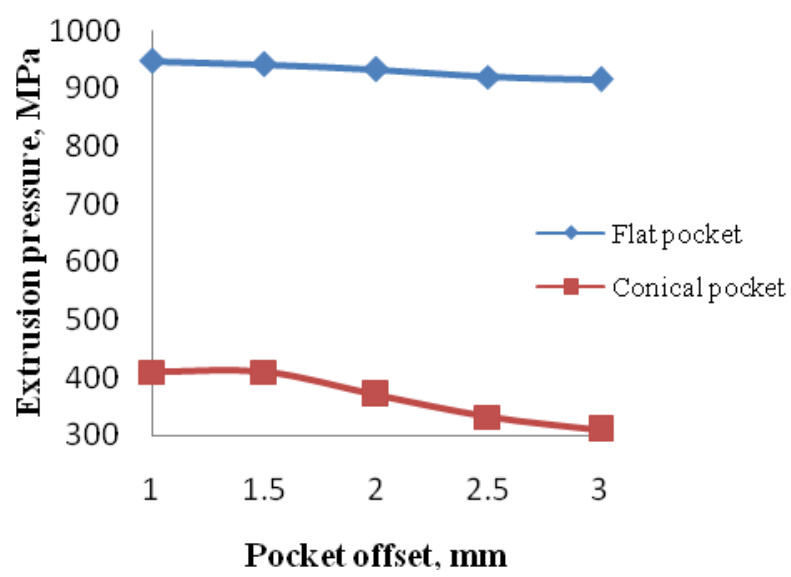

Figure 11. Extrusion pressure vs pocket offset 


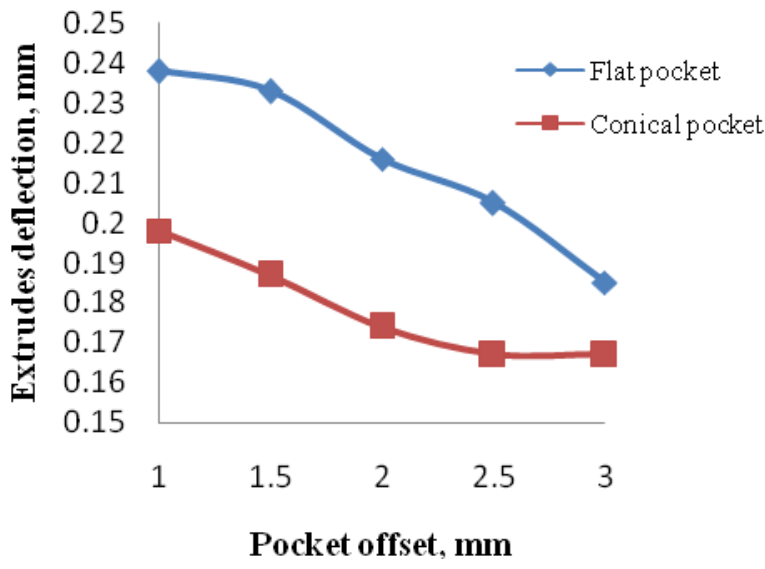

Figure 12. Extrudes deflection vs pocket offset

\section{Conclusion}

The paper has shown that control of extrusion pressure and extrudes deflection can be achieved using die bearing geometry parameters of die angle, die bearing length, pocket depth and offset. Flat pocket geometries achieve reduced product deflection, but like parallel bearings result in increased extrusion pressure or loads. To achieve reduced product deflection, the offset size should be large enough to provide enough velocity and easier flow of material. Better flow conditions are however obtained with conical die geometries to achieve minimized extrusion loads and product deflection as extrusion is predominantly by slip mechanism conditioned by the die angle.

\section{References}

[1] Goswami, R. K. Anandani, R.C., Sikand, R., Malik, I.A., Gupta, A.K. "Effects of extrusion parameters on mechanical properties of 2124AI-SiCp stir cast MMCs,” Mater. Trans. JIM 40 (3): 254-257, 1999.

[2] Pacanowski, J. and Zasadzinski, J. "The effect of selected parameters of aluminium extrusion on temperature changes in the die system,” Arch. Metall. 43 (4): 389-398, 1998.

[3] Schmoeckel, D., Vonschlotheim, G. F., Wansel, A. "Evaluation of the cold extrusion production process,"in: Proceedings of the $1^{\text {st }}$ Int. Symposium on Environmentally Conscious Design and Inverse Manufacturing, 186: 414-419, 1999.

[4] Onuh, S.O., Ekoja, M., Adeyemi, M.B. "Effects of die geometry and extrusion speed on cold extrusion of aluminium and lead alloys,” J. Mater. Proc. Tech., 132: 274-285, 2003.

[5] Kawalek, A., Milenin, A. Dyja, H. "Analysis of the effect of die shape on the state of strain in the process of extrusion of thinwalled aluminium sections,” Metallurgija, 44(2): 597-101, 2000.

[6] Ajiboye, J.S. and Adeyemi, M.B. "Effects of die land on the cold extrusion of lead alloy,” J. Mater. Proc. Tech., 171(3): 428-436, 2006.

[7] Gundu, D.T.andTuleun, L.T. "Empirical models for predicting extrusion pressure and section bending using die bearing length and reduction ratio," Int. J. Pure \& Appl. Sci., Pan-African, 1(2):64-69, 2008.

[8] Lontos, A.E., Soukatzidis, F.A., Demosthenous, D.A., Baldoukas, A.K. "Effect of Extrusion Parameters and die geometry on the produced billet quality using finite element method," in: Proceedings of the $3^{\text {rd }}$ Int. Conference on Manufacturing Engineering (ICMEN), 1-3 October 2008, Chalkidki, Greece, 215228.

[9] Chen, H.K., Chuang, W.C., Torng, S. "Finite element analysis of multi-hole extrusion of aluminium-alloy tubes,” J. Mater. Proc. Tech., 201: 150-155, 2008.

[10] Theodja, W.W., "Tribomechanical process on the die land area during extrusion of AA6063 alloy," in: Proceedings, $5^{\text {th }}$ International Extrusion Technology Seminar, Chicago, Illinois, 467-474, 1988.

[11] Lee, G.A. and Im, Y.T. "Analysis and die design of flat-die hot extrusion process 2. Numerical design of bearing lengths,” Int. $J$. Mech. Sci., 44: 935-946, 2002.

[12] Li, Q., Smith, C.J., Harris, C., Jolly, M.R. "Finite element investigations upon the influence of pocket die designs on metal flow in aluminium extrusion. Part I: Effect of pocket angle and volume on metal flow,” J. Mat. Proc. Tech., 135: 189-196, 2003.

[13] Li, Q., Smith, C.J., Harris, C., Jolly, M.R. "Finite element investigations upon the influence of pocket die designs on metal flow in aluminium extrusion. Part II: Effect of pocket geometry configurations on metal flow," J. Mat. Proc. Tech., 135: 197-203, 2003a.

[14] Sheppard, T. "Extrusion of Aluminium Alloys," Kluwer Academic Publishers, AA Dordrecht, Netherlands, IV, 1999,pp. 127-156, 170-185.

[15] Lof, J. "Elasto-viscoplastic FEM simulations of the aluminium flow in the die bearing area for extrusion of thin-walled sections," J. Mater. Proc. Tech., 114: 174-183, 2001.

[16] Altan, T., Wu, W., Li, G., Tang, J. "Finite element analysis of three- dimensional metal flow in cold and hot forming processes," CIRP Annals, 43(1): 235-239, 1994.

[17] Lof, J., Huetink, J., Nilsen, K.E. "FEM simulations of the material flow in the die bearing area of the aluminium extrusion process,"in: Proceedings of the $7^{\text {th }}$ International Extrusion Technology Seminar, Wauconda, Illinois, 2000, Vol. 2: 211-222.

[18] Muller, K.B. (). "Bending of extruded profiles during extrusion process,”J. Machine. Tools \& Manuf., 46(11): 1238-1242, 2006.

[19] Carmai, S.J.J, Pitakthapanaphong, S., Sechjarern. "3D finite element analysis of metal flow in hot aluminium extrusion of Tshaped profile with various offset pockets". J. Achievements in Mater. and Manuf. Eng., 31(2): 463-468, 2008.

[20] Gundu, D.T. "Investigations and numerical modelling of material flow in forward extrusion using pocket die bearings," Doctoral dissertation, University of Agriculture, Makurdi-Nigeria, 2010.

[21] Charkrabarty, J. “Theory of plasticity,” Int. Ed, McGraw-Hill, Inc., Singapore, 1987, 791p.

[22] Lof, J. and Huetink, J. "Numerical simulations of the aluminium extrusion process," in: Proceedings of the $2^{\text {nd }}$ ESAFORM Conference on Metal Forming, Guimaraes, Portugal, 1999, Ed: J.A. Covas, pp. 29-32.

[23] Tiernan, P., Draganescu, B., Hillery, M.T., "Modelling of extrusion force using the surface response method," Int. J. Manuf. Tech. 27: 48-52, 2005.

[24] Tan, X., Bay, N., Zhang, W. "Friction measurement and modeling in forward rod extrusion tests," in: Proceedings: IMechE, 217(J): 71-82, 2003.

[25] Yan, H. and Xia, J. "An approach to the optimal design of technological parameters in the profile extrusion process," Sci. \& Tech. Adv. Mater. 7: 127-131, 2006.

[26] Golovko, O., Mamuzic, I., Grydin, O. "Method for pocket die design on the basis of numerical investigations of aluminium extrusion process,” Metallurgija 45(3): 155-161, 2006. 